\title{
Transplantation of Nonexpanded Adipose Stromal Vascular Fraction and Platelet-Rich Plasma for Articular Cartilage Injury Treatment in Mice Model
}

\author{
Phuc Van Pham, ${ }^{1}$ Khanh Hong-Thien Bui, ${ }^{2}$ Dat Quoc Ngo, ${ }^{3}$ \\ Lam Tan Khuat, ${ }^{1}$ and Ngoc Kim Phan ${ }^{1}$ \\ ${ }^{1}$ Laboratory of Stem Cell Research and Application, University of Science, Vietnam National University, Ho Chi Minh City, Vietnam \\ ${ }^{2}$ University of Medical Center, Ho Chi Minh University of Medicine and Pharmacy, Ho Chi Minh City, Vietnam \\ ${ }^{3}$ Department of Pathology, University of Medicine and Pharmacy, Ho Chi Minh City, Vietnam
}

Correspondence should be addressed to Phuc Van Pham; pvphuc@hcmuns.edu.vn

Received 13 August 2012; Accepted 25 December 2012

Academic Editor: Ayako Oyane

Copyright (C) 2013 Phuc Van Pham et al. This is an open access article distributed under the Creative Commons Attribution License, which permits unrestricted use, distribution, and reproduction in any medium, provided the original work is properly cited.

\begin{abstract}
Stromal vascular fraction (SVF) combined with platelet-rich plasma (PRP) is commonly used in preclinical and clinical osteoarthritis as well as articular cartilage injury treatment. However, this therapy has not carefully evaluated the safety and the efficacy. This research aims to assess the safety and the efficacy of SVF combined with PRP transplantation. Ten samples of SVFs and PRPs from donors were used in this research. About safety, we evaluate the expression of some genes related to tumor formation such as Oct-4, Nanog, SSEA3, and SSEA4 by RT-PCR, flow cytometry, and tumor formation when injected in NOD/SCID mice. About efficacy, SVF was injected with PRP into murine joint that caused joint failure. The results showed that SVFs are negative with Oct-4, Nanog, SSEA-3, and SSEA-4, as well as they cannot cause tumors in mice. SVFs combined with PRP can improve the joint regeneration in mice. These results proved that SVFs combined with PRP transplantation is a promising therapy for articular cartilage injury treatment.
\end{abstract}

\section{Introduction}

Stem cell therapy is considered as a promising therapy for degenerative disease treatment, especially articular cartilage injury as well as osteoarthritis. Osteoarthritis was treated by stem cell transplantation for a few years ago. Stem cells from various sources were used to treat this disease. However, the mesenchymal stem cells (MSCs) are considered as most suitable candidates. MSCs are multipotential cells capable of differentiation into bone, cartilage, fat, and some other cells [1]. MSCs could be isolated from bone marrow [2], adipose tissue [3], cord blood [4], banked umbilical cord blood [5], umbilical cord [6], Wharton's jelly [7], placenta [8], and pulp [9]. However, MSCs from bone marrow [10-12] and from adipose tissue [13-15] are two common stem cell sources for treating cartilage degeneration.

Cartilage degeneration or cartilage injury is a common clinical problem and easily leads to osteoarthritis.
Osteoarthritis is a chronic degenerative process characterized by the degeneration of cartilage, bone bud formation, cartilage reorganization, joint erosion, and loss of joint function [16]. Currently, cartilage injury was treated primarily with drugs [17-20] or injection of hyaluronic acid [21, 22] to reduce the symptoms, pain, and inflammation control. However, these therapies's efficiencies were limited and often failed to prevent the degeneration of the joints [23].

MSCs from adipose tissue, also known as stem cells isolated from fat tissue (adipose-derived stem cells-ADSCs), are a suitable source of mesenchymal stem cells for autograft. This stem cell source was used to treat many diseases such as liver fibrosis [24], sciatic nerve defects [25], systemic sclerosis [26], ischemia [27], skeletal muscle injury [28], passive chronic immune thrombocytopenia [29], and infarcted myocardium [30]. Recently, they have been extended to treat cartilage injuries as well as osteoarthritis such as dogs [3133], rabbits [34], horses [14], rat [35], mice [36], and goats 
[37]. These researches demonstrated that neocartilage formed after ADSC transplantation. Some phase I and II clinical trials using ADSCs transplantation are performed to treat osteoarthritis and cartilage degeneration (NCT01300598, NCT01585857, NCT01399749). Pak (2011) showed that all ADSC grafted patients improved the cartilage regeneration [15].

Among all of ADSC transplantation cases, SVF is used as noncultured ADSC (nonexpanded ADSC). SVF transplantation has some advantages such as saving time (from isolation to transplant faster about 2-3 hours), being inexpensive, and reducing the risk of cell culture. Although many studies have demonstrated the benefits of SVF/ADSC transplantation in cartilage injury treatment, especially knee articular cartilage, so far a little comprehensive studies aim to evaluate the safety and efficiency of SVF transplantation for articular cartilage treatment. Therefore, this study aims to evaluate the safety and efficiency of SVF transplantation combined with PRP in the treatment of cartilage injury in the mouse model.

\section{Materials and Methods}

2.1. SVF and PRP Preparation. Firstly, adipose tissue was collected from abdominal fat tissue of ten consenting healthy donors. About 40-80 mL of fat was collected by syringe and stored in $100 \mathrm{~mL}$ sterile bottle. Fat was kept at $2-8^{\circ} \mathrm{C}$ and then quickly moved to the laboratory. SVF cells are separated from the fat using the extraction kits (Adistem, Australia) according to the manufacturer's guideline. Briefly, fat is washed 3 times with saline solution to eliminate red blood cells. Then, the fat was incubated with a solution AdiExtract (Adistem, Australia). The sample was centrifuged to collect SVF as pellet at the bottom of the tube. To prepare plateletrich plasma (PRP), $50 \mathrm{~mL}$ of peripheral blood was taken from a large vein (arm veins). Blood was centrifuged 1,700 rpm for 10 minutes to get platelet-enriching plasma. This plasma is activated with activator solution (Adistem, Australia). Then, PRP was mixed with SVF to make the cell suspension. Finally, this suspension was stimulated by the LED light (light monochromatic low energy, Adlight, Adistem, Australia) for 30 minutes before using for treatment.

2.2. Quantification of Nucleated Cells from SVF. Cell suspension (SVF and PRP) is used to count the nucleated cells. Cell number and percentage of viable cells were determined by automatically nucleus-based cell counter (NucleoCounter, Chemometec). Total cell numbers were counted after permeabilization of the membrane by Reagent A (lysis buffer, Chemometec) and neutralized with a solution of Reagent B (Neutralized buffer, Chemometec). Cell suspension is loaded into the counting chamber containing Propidium iodide dye. For counting dead cells, suspension cells were mixed with only Reagent B solution and loaded into the counting chamber. Survival rate is calculated as follows: (total cell number - the number of dead cells): the total number of cells $\times 100 \%$.

2.3. Evaluation of the Existence of ADSC in SVF. The existence of ADSC in SVF determined by flow cytometry. The process summarized as follows: cells were washed twice in physiological saline of Dulbecco-modified PBS (D-PBS) supplemented with $1 \%$ bovine serum albumin (Sigma-Aldrich, St Louis, MO). Cells were stained for $30 \mathrm{~min}$ at $4^{\circ} \mathrm{C}$ with the monoclonal antibody anti-CD44-PE, anti-CD90-PE, and anti-CD105-FITC (BD Biosciences, Franklin Lakes, New Jersey offers). Stained cells were analyzed by flow cytometer FACSCalibur machine (BD Biosciences). Isotype control is used for all analyzes.

2.4. RT-PCR. To evaluate the safety of SVF, we should identify the gene expression levels related to the process of causing tumors and test the ability to form tumors in vivo. About gene expression, RNA was isolate by Trizol according to the manufacturer's instructions (Sigma-Aldrich, St Louis, $\mathrm{MO})$. RNA precipitated with isopropanol at room temperature for 10 minutes. ADSC cells analyzed the expression of genes related to markers of cancer cells or embryonic stem cells, Oct-3/4 and Nanog by Real-time kit SYBR RTPCR one tube-one step (Sigma-Aldrich, St. Louis, MO). The used primers were Oct-3/4, forward primer: F: 5 GGAGGAAGCTGACAACAATGAAA-3', reverse primer R: 5 '-GGCCTGCACGAGGGTTT-3; Nanog, forward primer: F: 5 '-ACAACTGGCCGAAGAATAGCA-3'; reverse primer R: 5 -GGTTCCCAGTCGGGTTCAC-3; GAPDH, forward primer: F: 5'-GGGCTGCTTTTAACTCTGGT-3'; reverse primer: R: 5 -TGGCAGGTTTTTCTAGACGG-3' .

2.5. In Vivo Tumorigenicity Assay. The tumorigenicity of ADSC was evaluated in mice NOD/SCID (NOD.CB17Prkdcscid/J, Charles River Laboratories). All mice manipulation was according to guideline of laboratory and approved by the Local Ethics Committee of Stem Cell Research and Application, University of Science (VNU-HCM, VN). All mice were kept in clean condition. Mice were injected subcutaneously at a concentration of $10^{5}, 10^{6}$, and $10^{7}$ cells, respectively in three groups (each group with 3 mice). Control group was injected with PBS. The formation of tumors in mice was followed for 3 months.

2.6. Articular Cartilage Injured Mice Model and Experimental Treatment Schedule. To evaluate the efficiency of SVF transplantation in articular cartilage injury, we used articular cartilage injured mouse model. The NOD mouse/SCID mice were anesthetized with ketamine $(40 \mathrm{mg} / \mathrm{kg})$, then joint destruction by fine needle $32.5 \mathrm{G}$. Normal mice were used as a positive control (uninjured). Nine mice randomly divided into the treatment group ( 5 mice) and negative control group (4 mice). Six hours after injury, the mice were treated. In the treatment group, $200 \mu \mathrm{L}$ containing $2 \cdot 10^{6} \mathrm{SVF}$ in PRP (the treatment group) or PBS (the negative control group) was injected into the knee joint via two doses, with a $10 \mathrm{~min}$ interval between injections.

Mice were recorded some parameters related to joint regeneration for 45 days. The mice were recorded the movement on the table daily. At the 45th day, all mice were anesthetized, and their hind limbs were cut and used for 


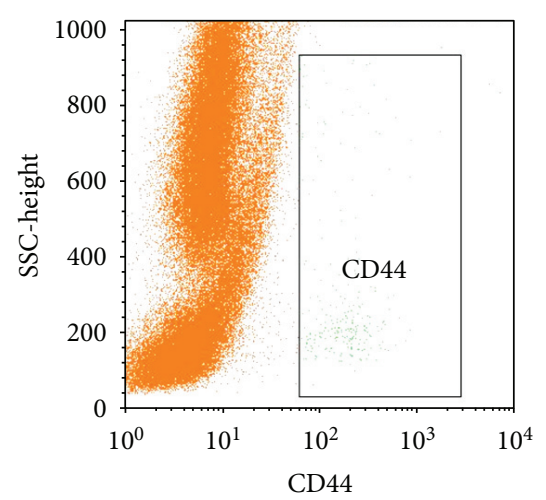

(a)

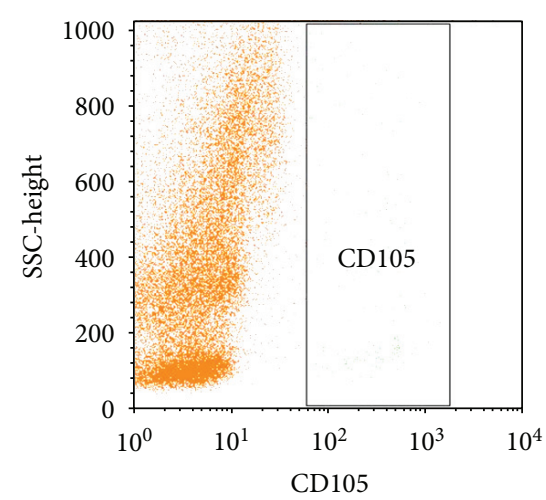

(b)

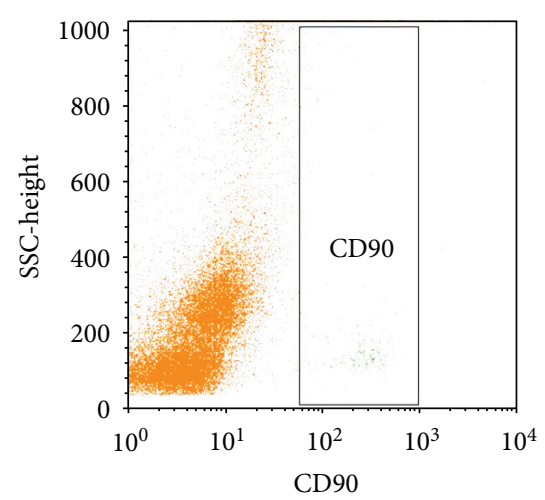

(c)

FIGURE 1: Existence of ADSCs in SVF. ADSCs were confirmed based on expression of CD44, CD105 and CD90.

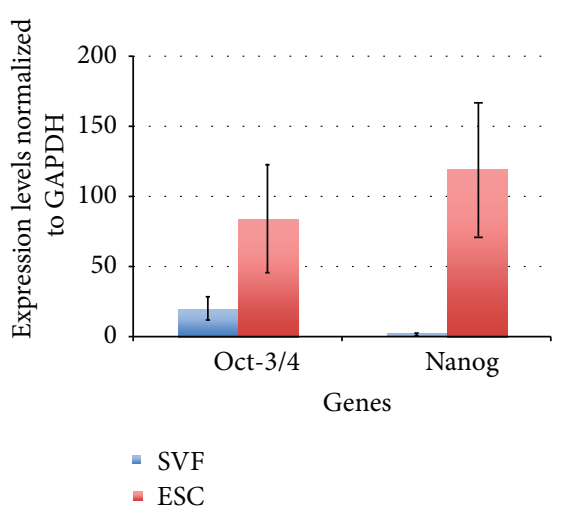

(a)

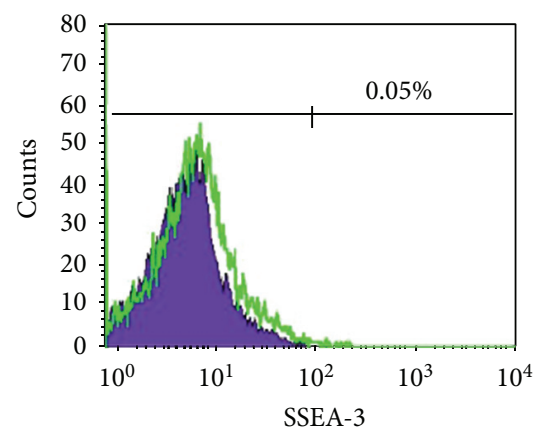

(b)

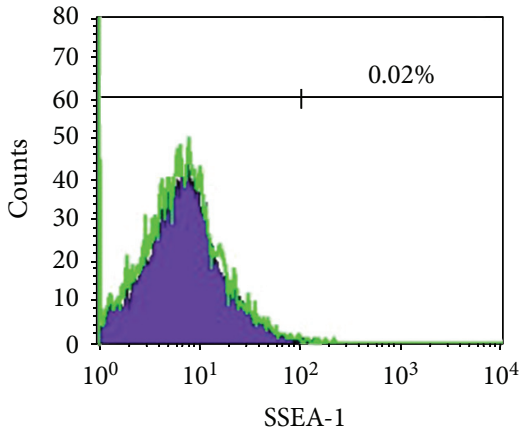

(c)

FIGURE 2: Expression of Oct-3/4, Nanog, SSEA-3, and SSEA-1 in SVF. Oct-3/4 and Nanog expressed lower in embryonic stem cell (ESC) (a); while SSEA-3 and SSEA-1 did not express in SVF (b and c).

histological analysis and further experiments. The samples were fixed in $10 \%$ formalin, decalcified, sectioned longitudinally, and stained with hematoxylin and eosin (HE) (SigmaAldrich, St Louis, MO). Using HE stained slides, three parameters were examined such as the area of injured cartilage (\%), the area of neo-cartilage (\%), and the number of neocartilage cell layers. The injured cartilage area was determined as the percentage of lost mature cartilage compared to the control. Data was analyzed using Statgraphics software (v7.0; Statgraphics Graphics System, Warrenton, VA).

\section{Results and Discussion}

MSCs have the large differentiative potential, easily differentiate into bone, cartilage, and adipocyte. Autologous MSC transplantation is considered as a safe and effective therapy in some patients. Recently, adipose tissue was identified as the abundant source of MSCs. ADSCs exist with large amounts of adipose tissue [38]. Similar to MSCs from other sources, ADSC have the ability to differentiate into fat cells, bone, and cartilage and transdifferentiate into neurons and muscle [3945]. Therefore, ADSC is favored as a source of autologous cell transplantation. However, the isolated ADSC relatively complex, consuming time, so ADSCs were mainly used as SVF (containing ADSC) without culture. This study aims to evaluate the safety and efficiency of SVF transplantation resuspended in PRP in mouse model.

In the first experiment, we successfully isolated SVF and PRP. Compared to other studies, we have successfully isolated $0.32 \pm 0.15 \times 10^{6} \mathrm{SVF}$ cells from 1 gram of fat with a survival rate of $90.90 \% \pm 8.57 \%(n=10)$. Next, we assessed the existence of ADSC or MSC in the SVF. Analysis results from 10 samples showed that ADSCs existed in all samples. ADSC counted to $0.89 \% \pm 0.11 \%$ in the SVF. ADSC populations were identified based on the expression of CD44, CD90, and CD105 of them (Figure 1). These results were similar to many other authors on ADSC markers [43, 4652]. The markers satisfied the criteria of MSC following to Dominici et al. (2006) [53].

To assess safety, we have evaluated the expression of genes related to cancer. In particular, two genes Oct-3/4 and Nanog were assessed by real-time RT-PCR method and SSEA-3, and SSEA-1 was assessed by flow cytometry. The results showed expression of Oct-3/4, Nanog, SSEA-3, and SSEA-1 much lower than embryonic stem cells (Figure 2). These results demonstrated that the SVF hold low tumorigenicity. In fact, 


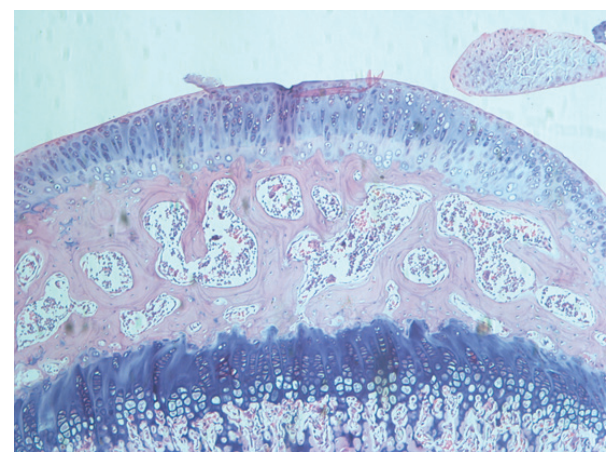

(a)

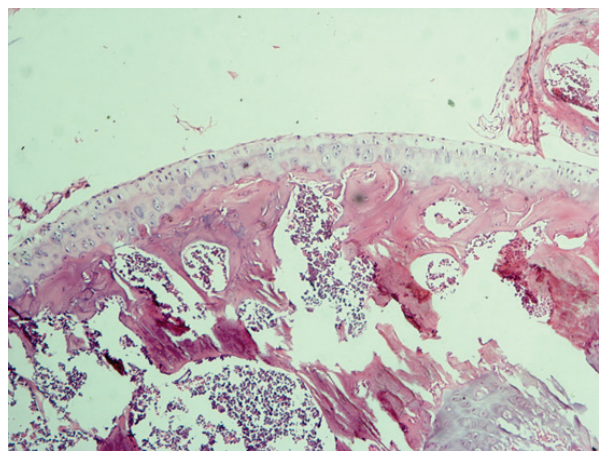

(c)

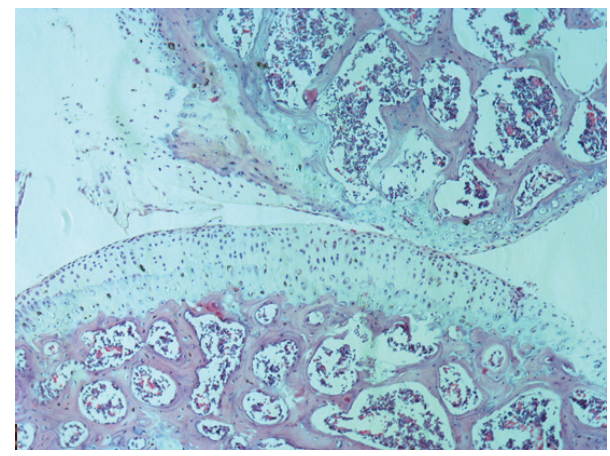

(e)

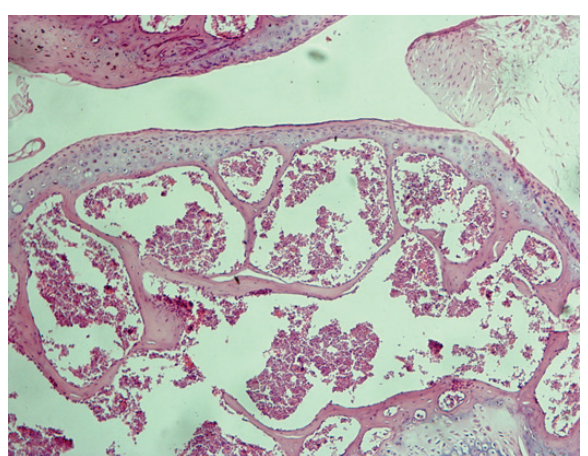

(b)

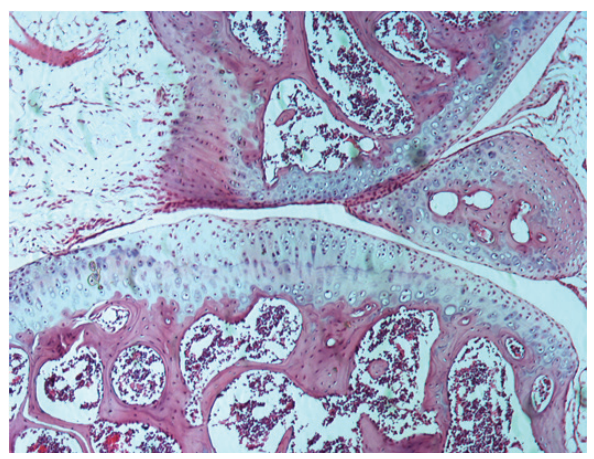

(d)

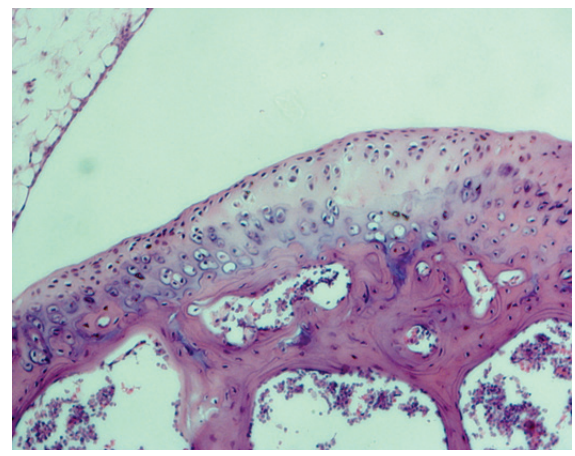

(f)

FIGURE 3: HE staining of articular cartilage. Mature cartilage layer was recorded in normal mouse (a). Mature cartilage was thinned by needle (b). Injured cartilage was regenerated in negative control group $(c, e)$ and treated group $(\mathrm{d}, \mathrm{f})$. However, the neocartilage in treated group was thicker than in negative control group.

Nanog and Oct-3/4 participate in the process of self-renewal of embryonic stem cells $[54,55]$. Moreover, these proteins related to the tumorigenicity process in mature germ cells [56], carcinoma oral squamous cell [57], lung cancer [58], breast cancer [59], and gliomas [60]. The SVF and PRP injection under the skin mouse NOD/SCID could not form teratomas. With these experiments, we concluded that the SVF plus PRP has a promising therapy with a high safety for transplantation experiments.

In the next experiment, we evaluated the efficiency of SVF transplantation in articular cartilage injury. The results showed that the SVF plus PRP transplantation significantly improved the articular cartilage injury compared to control. In the treated group, mice exhibited a reduction of the time required that mice could move on the table by injured hind limb compared to control. In the control group, mice can move by injured legs after $38.5 \pm 4.30$ days, while in the treated group, mice could move by injured legs after $29.4 \pm$ 4.32 days.

About histological analysis, in the treated group, an average area of the cartilage damage was $62.60 \%$, and there was $35.5 \%$ of neocartilage formation after 45 days $(n=5)$. While in the control group, average area of cartilage lesions was $53.13 \%$, but only $15.5 \%$ of neocartilage formation after 45 days (Figure 3 ).

The grade of cartilage injury between two experimental groups was different due to the effects of the dissimilar force from needle. After 45 days, results showed that $35.5 \%$ of neocartilage formed in treated group, while only $15.5 \%$ of neocartilage formed in the negative control group. This 
suggested that SVF and PRP gave benefit effects on the enhancement as well as trigger the neocartilage forming. More importantly, the articular cartilage in both of groups completed at the same level after 45 days with 12 cell layers. These results demonstrated that the SVF and PRP could participate in the process of self-renewal of joint cartilage at the joint microenvironment. Especially, there were no scar tissues or tumors forming at the graft sites. This result was similar to the previous publications about SVF plus PRP transplantation in the treatment of cartilage injury in dog [31-33], rabbits [34, 61], horses [14, 61], rat [35], mice [36], and goats [37]. For example, in joint injured mice model by collagenase, Ter Huurne et al. (2011) showed that the level of damage nearly $50 \%$ reduction in ADSC transplanted mice compared to control after 42 days [36]. Specifically, knee injury went down to $25 \%$ in treated mice compare to $88 \%$ in controls. They suggested that the transplanted ADSC protected and healed of injured cartilage [37]. The findings of Dragoo et al. (2007) showed that autologous ADSCs could reestablish the joint surface in rabbits, in which $100 \%$ of rabbits $(12 / 12)$ had the occurrence of neocartilage, while only $8 \%$ rabbit $(1 / 12)$ in the control had the appearance of neocartilage $(P<0.001)$ [62].

Roles of SVF or ADSCs in cartilage regeneration were recorded with many different effects. In fact, similar to MSCs derived from bone marrow, ADSC had anti-inflammatory properties $[63,64]$ and inhibition of graft versus host disease (GVHD) [65]. The transplantation of ADSC could successfully treat graft versus host disease with steroid-resistant form $[66,67]$. All of these roles could add more effects to trigger rapid cartilage regeneration in this study.

Besides, in this study, ingredients from PRP also had important roles in stimulated grafted cells as well as endogenous cells growth and differentiation. There are at least six known growth factors such as platelet-derived growth factor (PDGF) that promotes blood vessel growth, cell division, and forming the skin; transforming growth factor-beta (TGF- $\beta$ ) that promotes cell division mitosis and bone metabolism; vascular endothelial growth factor (VEGF) that promotes the blood vessel formation; epidermal growth factor (EGF) that promotes cell growth and differentiation, angiogenesis, and collagen formation; fibroblast growth factor-2 (FGF-2) that promotes the growth of cell differentiation and angiogenesis; and insulin-like growth factor (IGF) that is a regulator in all cell types of the body $[68,69]$. PRP injection also showed that improvements in knee injury and osteoarthritis score, including pain and symptom relief $[70,71]$.

Combining effect of SVF and PRP has a positive effect on the stimulation of proliferation, differentiation, and regeneration of cartilage in a mouse model. However, SVF also has a few limitations, notably the relatively low presence of ADSCs in the SVF. Therefore, SVF cultured to enrich ADSC before being transplanted may be essential, especially a little obtained fat cases.

\section{Conclusion}

Adipose tissue provides a rich source of MSCs. The SVF and PRP injection are a promising therapy in injured articular cartilage regeneration. This therapy significantly improved the injured articular cartilage. However, this study only assesses the ability of tumorigenicity and efficiency in mouse. Some side effects such as fever and muscle pain as well as the tumorigenicity in human being when using SVF and PRP could not be checked in this research.

\section{Abbreviations}

SVF: $\quad$ Stromal vascular fraction

PRP: $\quad$ Platelet-rich plasma

RT-PCR: Reverse transcription polymerase chain reaction

NOD/SCID: Nonobese diabetic/severe combined immunodeficient

SSEA: $\quad$ Stage-specific embryonic antigen

MSC: $\quad$ Mesenchymal stem cell

ADSC: $\quad$ Adipose-derived stem cell

D-PBS: Dulbecco-modified phosphate buffered

HE: $\quad$ Hematoxylin and eosin

ESC: $\quad$ Embryonic stem cell

GVHD: Graft versus host disease.

\section{References}

[1] D. J. Prockop, "Marrow stromal cells as stem cells for nonhematopoietic tissues," Science, vol. 276, pp. 71-74, 1997.

[2] S. M. Phadnis, M. V. Joglekar, M. P. Dalvi et al., "Human bone marrow-derived mesenchymal cells differentiate and mature into endocrine pancreatic lineage in vivo," Cytotherapy, vol. 13, no. 3, pp. 279-293, 2011.

[3] B. T. Estes, B. O. Diekman, J. M. Gimble, and F. Guilak, "Isolation of adipose-derived stem cells and their induction to a chondrogenic phenotype," Nature Protocols, vol. 5, no. 7, pp. 1294-1311, 2010.

[4] A. Reinisch, C. Bartmann, E. Rohde et al., "Humanized system to propagate cord blood-derived multipotent mesenchymal stromal cells for clinical application," Regenerative Medicine, vol. 2, no. 4, pp. 371-382, 2007.

[5] P. V. Phuc, T. H. Nhung, D. T. T. Loan, D. C. Chung, and P. K. Ngoc, "Differentiating of banked human umbilical cord bloodderived mesenchymal stem cells into insulin-secreting cells," In Vitro Cellular and Developmental Biology-Animal, vol. 47, no. 1, pp. 54-63, 2011.

[6] V. A. Farias, J. L. Linares-Fernández, J. L. Peñalver et al., "Human umbilical cord stromal stem cell express CD10 and exert contractile properties," Placenta, vol. 32, pp. 86-95, 2011.

[7] J. Peng, Y. Wang, L. Zhang et al., "Humanumbilical cord Wharton's jelly-derived mesenchymal stem cells differentiate into a Schwann-cell phenotype and promote neurite outgrowth in vitro," Brain Research Bulletin, vol. 84, pp. 235-243, 2011.

[8] G. A. Pilz, C. Ulrich, M. Ruh et al., "Human term placentaderived mesenchymal stromal cells are less prone to osteogenic differentiation than bone marrow-derived mesenchymal stromal cells," Stem Cells and Development, vol. 20, no. 4, pp. 635-646, 2011.

[9] L. Spath, V. Rotilio, M. Alessandrini et al., "Explant-derived human dental pulp stem cells enhance differentiation and proliferation potentials," Journal of Cellular and Molecular Medicine, vol. 14, pp. 1635-1644, 2010. 
[10] A. M. Lubis and V. K. Lubis, "Adult bone marrow stem cells in cartilage therapy," Acta Medica Indonesiana, vol. 44, pp. 62-68, 2012.

[11] C. Kasemkijwattana, S. Hongeng, S. Kesprayura, V. Rungsinaporn, K. Chaipinyo, and K. Chansiri, "Autologous bone marrow mesenchymal stem cells implantation for cartilage defects: two cases report," Journal of the Medical Association of Thailand, vol. 94, no. 3, pp. 395-400, 2011.

[12] F. Davatchi, B. S. Abdollahi, M. Mohyeddin, F. Shahram, and B. Nikbin, "Mesenchymal stem cell therapy for knee osteoarthritis. Preliminary report of four patients," International Journal of Rheumatic Diseases, vol. 14, no. 2, pp. 211-215, 2011.

[13] D. Minteer, K. G. Marra, and J. P. Rubin, "Adipose-derived mesenchymal stem cells: biology and potential applications," Advances in Biochemical Engineering/Biotechnology. In press.

[14] D. D. Frisbie, J. D. Kisiday, C. E. Kawcak, N. M. Werpy, and C. W. McIlwraith, "Evaluation of adipose-derived stromal vascular fraction or bone marrow-derived mesenchymal stem cells for treatment of osteoarthritis," Journal of Orthopaedic Research, vol. 27, no. 12, pp. 1675-1680, 2009.

[15] J. Pak, "Regeneration of human bones in hip osteonecrosis and human cartilage in knee osteoarthritis with autologous adiposetissue-derived stem cells: a case series," Journal of Medical Case Reports, vol. 5, p. 296, 2011.

[16] H. A. Wieland, M. Michaelis, B. J. Kirschbaum, and K. A. Rudolphi, "Osteoarthritis-an untreatable disease?" Nature Reviews Drug Discovery, vol. 4, pp. 331-344, 2005.

[17] J. A. Buckwalter, C. Saltzman, and T. Brown, "The impact of osteoarthritis: implications for research," Clinical Orthopaedics and Related Research, vol. 427, pp. S6-S15, 2004.

[18] M. Dougados, "The role of anti-inflammatory drugs in the treatment of osteoarthritis: a European viewpoint," Clinical and Experimental Rheumatology, vol. 19, pp. S9-S14, 2001.

[19] T. Pincus, G. G. Koch, T. Sokka et al., "A randomized, doubleblind, crossover clinical trial of diclofenac plus misoprostol versus acetaminophen in patients with osteoarthritis of the hip or knee," Arthritis \& Rheumatism, vol. 44, pp. 1587-1598, 2001.

[20] S. Eyigor, S. Hepguler, M. Sezak, F. Öztop, and K. Capaci, "Effects of intra-articular hyaluronic acid and corticosteroid therapies on articular cartilage in experimental severe osteoarthritis," Clinical and Experimental Rheumatology, vol. 24, no. 6, p. 724, 2006.

[21] T. Spaková, J. Rosocha, M. Lacko, D. Harvanová, and A. Gharaibeh, "Treatment of knee joint osteoarthritis with autologous platelet-rich plasma in comparison with hyaluronic acid," American Journal of Physical Medicine and Rehabilitation, vol. 91, no. 5, pp. 411-417, 2012.

[22] V. Karatosun, B. Unver, A. Ozden, Z. Ozay, and I. Gunal, "Intra-articular hyaluronic acid compared to exercise therapy in osteoarthritis of the ankle. A prospective randomized trial with long-term follow-up," Clinical and Experimental Rheumatology, vol. 26, no. 2, pp. 288-294, 2008.

[23] J. P. Schroeppel, J. D. Crist, H. C. Anderson, and J. Wang, "Molecular regulation of articular chondrocyte function and its significance in osteoarthritis," Histology and Histopathology, vol. 26, pp. 377-394, 2011.

[24] H. J. Harn, S. Z. Lin, S. H. Hung et al., "Adipose-derived stem cells can abrogate chemical-induced liver fibrosis and facilitate recovery of liver function," Cell Transplantation. In press.

[25] J. H. Gu, Y. H. Ji, E. S. Dhong, D. H. Kim, and E. S. Yoon, "Transplantation of adipose derived stem cells for peripheral nerve regeneration in sciatic nerve defects of the rat," Current Stem Cell Research \& Therapy, vol. 7, no. 5, pp. 347-355, 2012.

[26] N. Scuderi, S. Ceccarelli, M. G. Onesti et al., "Human adipose derived stem cells for cell based therapies in the treatment of systemic sclerosis," Cell Transplantation. In press.

[27] M. Mazo, S. Hernández, J. J. Gavira et al., "Treatment of reperfused ischemia with adipose-derived stem cells in a preclinical swine model of myocardial infarction," Cell Transplantation. In press.

[28] R. Peçanha, L. L. Bagno, M. B. Ribeiro et al., "Adipose-derived stem-cell treatment of skeletal muscle injury," The Journal of Bone \& Joint Surgery, vol. 94, pp. 609-617, 2012.

[29] J. Xiao, C. Zhang, Y. Zhang et al., "Transplantation of adiposederived mesenchymal stem cells into a murine model of passive chronic immune thrombocytopenia," Transfusion, vol. 52, no. 12, pp. 2551-2558, 2012.

[30] J. J. Yang, X. Yang, Z. Q. Liu et al., “Transplantation of adipose tissue-derived stem cells overexpressing heme oxygenase-1 improves functions and remodeling of infarcted myocardium in rabbits," The Tohoku Journal of Experimental Medicine, vol. 226, pp. 231-241, 2012.

[31] L. L. Black, J. Gaynor, C. Adams et al., "Effect of intraarticular injection of autologous adipose-derived mesenchymal stem and regenerative cells on clinical signs of chronic osteoarthritis of the elbow joint in dogs," Veterinary Therapeutics, vol. 9, no. 3, pp. 192-200, 2008.

[32] L. L. Black, J. Gaynor, D. Gahring et al., "Effect of adiposederived mesenchymal stem and regenerative cells on lameness in dogs with chronic osteoarthritis of the coxofemoral joints: a randomized, double-blinded, multicenter, controlled trial," Veterinary Therapeutics, vol. 8, no. 4, pp. 272-284, 2007.

[33] A. Guercio, P. Di Marco, S. Casella et al., "Production of canine mesenchymal stem cells from adipose tissue and their application in dogs with chronic osteoarthritis of the humeroradial joints," Cell Biology International, vol. 36, pp. 189-194, 2012.

[34] F. S. Toghraie, N. Chenari, M. A. Gholipour et al., "Treatment of osteoarthritis with infrapatellar fat pad derived mesenchymal stem cells in Rabbit," Knee, vol. 18, no. 2, pp. 71-75, 2011.

[35] J. M. Lee and G. I. Im, "SOX trio-co-transduced adipose stem cells in fibrin gel to enhance cartilage repair and delay the progression of osteoarthritis in the rat," Biomaterials, vol. 33, pp. 2016-2024, 2012.

[36] M. C. ter Huurne, P. L. E. M. van Lent, A. B. Blom et al., "A single injection of adipose-derived stem cells protects against cartilage damage and lowers synovial activation in experimental osteoarthritis," Arthritis \& Rheumatism, vol. 63, p. 1784, 2011.

[37] J. M. Gimble and F. Guilak, "Differentiation potential of adipose derived adult stem cell (ADAS) cells," Current Topics in Developmental Biology, vol. 58, pp. 137-160, 2003.

[38] J. M. Murphy, D. J. Fink, E. B. Hunziker, and F. P. Barry, "Stem cell therapy in a caprine model of osteoarthritis," Arthritis \& Rheumatism, vol. 48, pp. 3464-3474, 2003.

[39] P. A. Zuk, M. Zhu, H. Mizuno et al., "Multilineage cells from human adipose tissue: implications for cell-based therapies," Tissue Engineering, vol. 7, no. 2, pp. 211-228, 2001.

[40] Y. D. C. Halvorsen, D. Franklin, A. L. Bond et al., "Extracellular matrix mineralization and osteoblast gene expression by human adipose tissue-derived stromal cells," Tissue Engineering, vol. 7, no. 6, pp. 729-741, 2001.

[41] H. Mizuno, P. A. Zuk, M. Zhu, H. P. Lorenz, P. Benhaim, and M. H. Hedrick, "Myogenic differentiation by human processed 
lipoaspirate cells," Plastic and Reconstructive Surgery, vol. 109, pp. 199-209, 2002.

[42] W. Wagner, F. Wein, A. Seckinger et al., "Comparative characteristics of mesenchymal stem cells from human bone marrow, adipose tissue, and umbilical cord blood," Experimental Hematology, vol. 33, no. 11, pp. 1402-1416, 2005.

[43] S. Kern, H. Eichler, J. Stoeve, H. Klüter, and K. Bieback, "Comparative analysis of mesenchymal stem cells from bone marrow, umbilical cord blood, or adipose tissue," Stem Cells, vol. 24, no. 5, pp. 1294-1301, 2006.

[44] K. M. Safford, K. C. Hicok, S. D. Safford et al., "Neurogenic differentiation of murine and human adipose-derived stromal cells," Biochemical and Biophysical Research Communications, vol. 294, no. 2, pp. 371-379, 2002.

[45] R. Izadpanah, C. Trygg, B. Patel et al., "Biologic properties of mesenchymal stem cells derived from bone marrow and adipose tissue," Journal of Cellular Biochemistry, vol. 99, no. 5, pp. 1285-1297, 2006.

[46] A. N. Patel, J. Yochman, V. Vargas, and D. A. Bull, "Putative population of adipose derived stem cells isolated from mediastinal tissue during cardiac surgery," Cell Transplantation. In press.

[47] G. Musumeci, D. Lo Furno, C. Loreto et al., "Mesenchymal stem cells from adipose tissue which have been differentiated into chondrocytes in three-dimensional culture express lubricin," Experimental Biology and Medicine, vol. 236, pp. 1333-1341, 2011.

[48] V. Zachar, J. G. Rasmussen, and T. Fink, "Isolation and growth of adipose tissue-derived stem cells," Methods in Molecular Biology, vol. 698, pp. 37-49, 2011.

[49] C. K. Rebelatto, A. M. Aguiar, M. P. Moretão et al., "Dissimilar differentiation of mesenchymal stem cells from bone marrow, umbilical cord blood, and adipose tissue," Experimental Biology and Medicine, vol. 233, no. 7, pp. 901-913, 2008.

[50] I. S. Blande, V. Bassaneze, C. Lavini-Ramos et al., "Adipose tissue mesenchymal stem cell expansion in animal serum-free medium supplemented with autologous human platelet lysate," Transfusion, vol. 49, no. 12, pp. 2680-2685, 2009.

[51] C. Dromard, P. Bourin, M. André, S. De Barros, L. Casteilla, and V. Planat-Benard, "Human adipose derived stroma/stem cells grow in serum-free medium as floating spheres," Experimental Cell Research, vol. 317, no. 6, pp. 770-780, 2011.

[52] D. T. B. Shih, J. C. Chen, W. Y. Chen, Y. P. Kuo, C. Y. Su, and T. Burnouf, "Expansion of adipose tissue mesenchymal stromal progenitors in serum-free medium supplemented with virally inactivated allogeneic human platelet lysate," Transfusion, vol. 51, no. 4, pp. 770-778, 2011.

[53] M. Dominici, K. Le Blanc, I. Mueller et al., "Minimal criteria for defining multipotent mesenchymal stromal cells. The International Society for Cellular Therapy position statement," Cytotherapy, vol. 8, no. 4, pp. 315-317, 2006.

[54] H. Niwa, J. Miyazaki, and A. G. Smith, "Quantitative expression of Oct-3/4 defines differentiation, dedifferentiation or selfrenewal of ES cells," Nature Genetics, vol. 24, pp. 372-376, 2000.

[55] K. Mitsui, Y. Tokuzawa, H. Itoh et al., “The homeoprotein nanog is required for maintenance of pluripotency in mouse epiblast and ES cells," Cell, vol. 113, no. 5, pp. 631-642, 2003.

[56] K. Hochedlinger, Y. Yamada, C. Beard, and R. Jaenisch, "Ectopic expression of Oct-4 blocks progenitor-cell differentiation and causes dysplasia in epithelial tissues," Cell, vol. 121, no. 3, pp. 465-477, 2005.
[57] S. H. Chiou, C. C. Yu, C. Y. Huang et al., "Positive correlations of Oct-4 and Nanog in oral cancer stem-like cells and high-grade oral squamous cell carcinoma," Clinical Cancer Research, vol. 14, no. 13, pp. 4085-4095, 2008.

[58] Y. C. Chen, H. S. Hsu, Y. W. Chen et al., "Oct-4 expression maintained cancer stem-like properties in lung cancer-derived CD133-positive cells," PLoS One, vol. 3, article e2637, 2008.

[59] C. Liu, X. Cao, Y. Zhang et al., "Co-expression of Oct-4 and Nestin in human breast cancers," Molecular Biology Reports, vol. 39, pp. 5875-5881, 2012.

[60] Y. Guo, S. Liu, P. Wang et al., "Expression profile of embryonic stem cell-associated genes Oct4, Sox 2 and Nanog in human gliomas," Histopathology, vol. 59, pp. 763-775, 2011.

[61] J. T. Oliveira, L. S. Gardel, T. Rada, L. Martins, M. E. Gomes, and R. L. Reis, "Injectable gellan gum hydrogels with autologous cells for the treatment of rabbit articular cartilage defects," Journal of Orthopaedic Research, vol. 28, no. 9, pp. 1193-1199, 2010.

[62] J. L. Dragoo, G. Carlson, F. McCormick et al., "Healing fullthickness cartilage defects using adipose-derived stem cells," Tissue Engineering, vol. 13, no. 7, pp. 1615-1621, 2007.

[63] P. F. Caimi, J. Reese, Z. Lee, and H. M. Lazarus, "Emerging therapeutic approaches for multipotent mesenchymal stromal cells," Current Opinion in Hematology, vol. 17, no. 6, pp. 505-513, 2010.

[64] N. G. Singer and A. I. Caplan, "Mesenchymal stem cells: mechanisms of inflammation," Annual Review of Pathology, vol. 6, pp. 457-478, 2011.

[65] O. Ringdén, M. Uzunel, I. Rasmusson et al., "Mesenchymal stem cells for treatment of therapy-resistant graft-versus-host disease," Transplantation, vol. 81, no. 10, pp. 1390-1397, 2006.

[66] B. Fang, Y. Song, L. Liao, Y. Zhang, and R. C. Zhao, "Favorable response to human adipose tissue-derived mesenchymal stem cells in steroid-refractory acute graft-versus-host disease," Transplantation Proceedings, vol. 39, no. 10, pp. 3358-3362, 2007.

[67] B. Fang, Y. Song, R. C. Zhao, Q. Han, and Q. Lin, "Using human adipose tissue-derived mesenchymal stem cells as salvage therapy for hepatic graft-versus-host disease resembling acute hepatitis," Transplantation Proceedings, vol. 39, no. 5, pp. 1710-1713, 2007.

[68] P. Borrione, A. D. Gianfrancesco, M. T. Pereira, and F. Pigozzi, "Platelet-rich plasma in muscle healing," American Journal of Physical Medicine \& Rehabilitation, vol. 89, pp. 854-861, 2010.

[69] W. Yu, J. Wang, and J. Yin, "Platelet-rich plasma: a promising product for treatment of peripheral nerve regeneration after nerve injury," International Journal of Neuroscience, vol. 121, pp. 176-180, 2011.

[70] S. Sampson, M. Reed, H. Silvers, M. Meng, and B. Mandelbaum, "Injection of platelet-rich plasma in patients with primary and secondary knee osteoarthritis: a pilot study," American Journal of Physical Medicine \& Rehabilitation, vol. 89, no. 12, pp. 961-969, 2010.

[71] G. Filardo, E. Kon, R. Buda et al., "Platelet-rich plasma intraarticular knee injections for the treatment of degenerative cartilage lesions and osteoarthritis," Knee Surgery, Sports Traumatology, Arthroscopy, vol. 19, no. 4, pp. 528-535, 2011. 

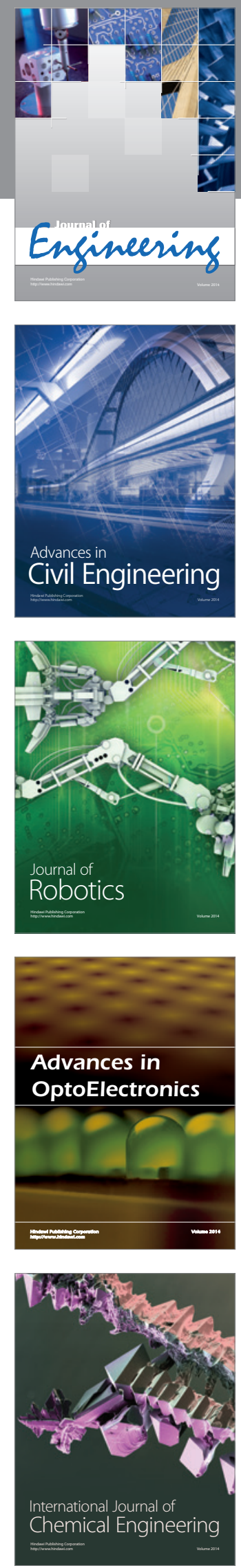

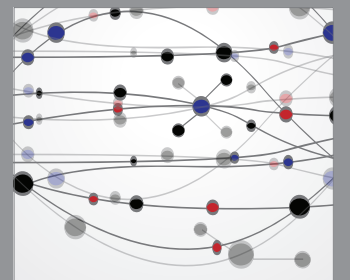

The Scientific World Journal
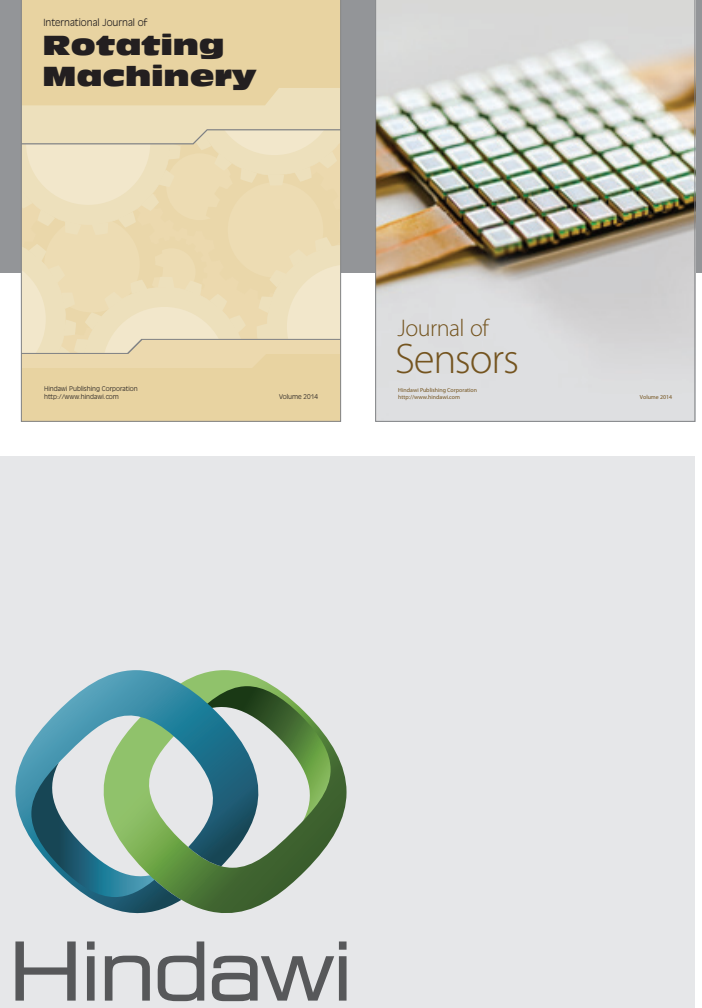

Submit your manuscripts at http://www.hindawi.com
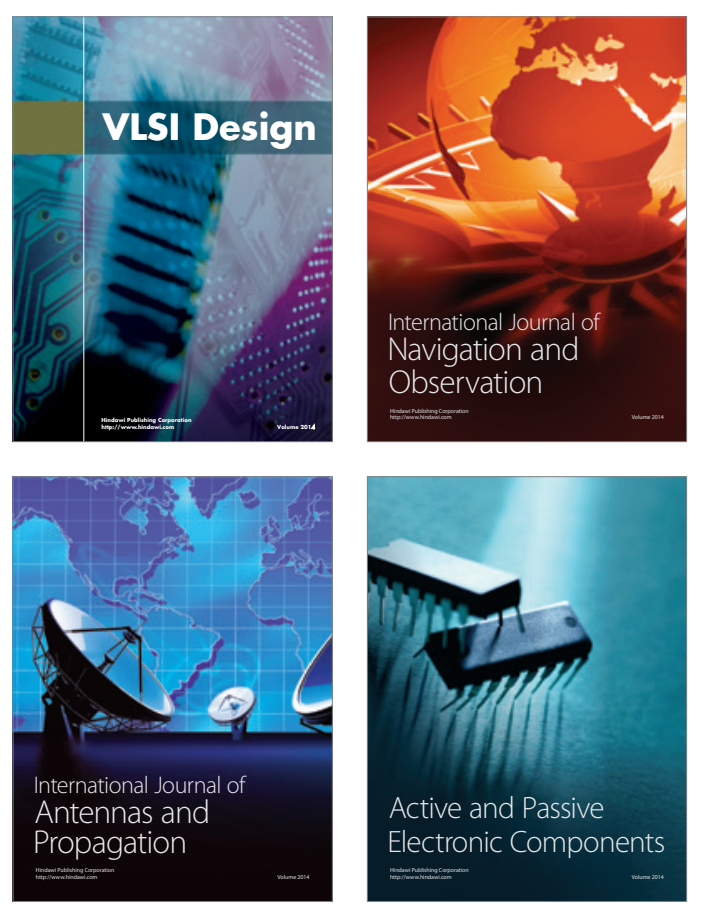
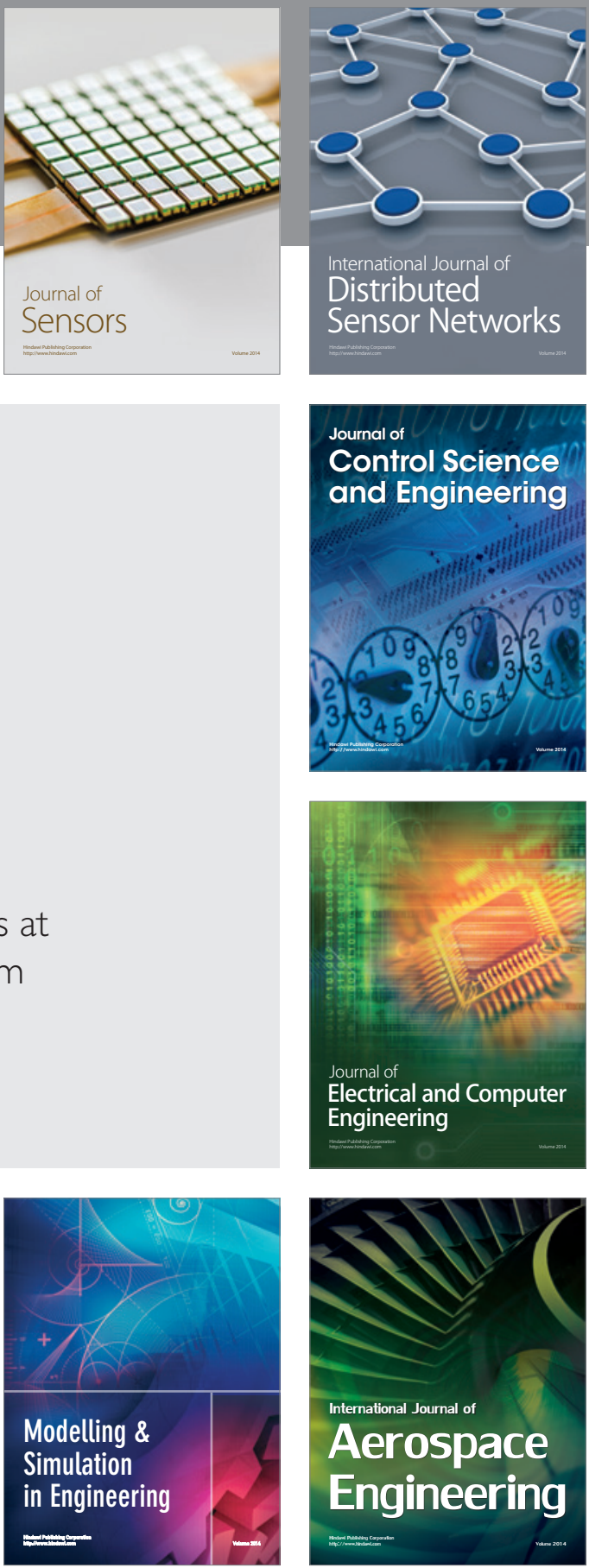

Journal of

Control Science

and Engineering
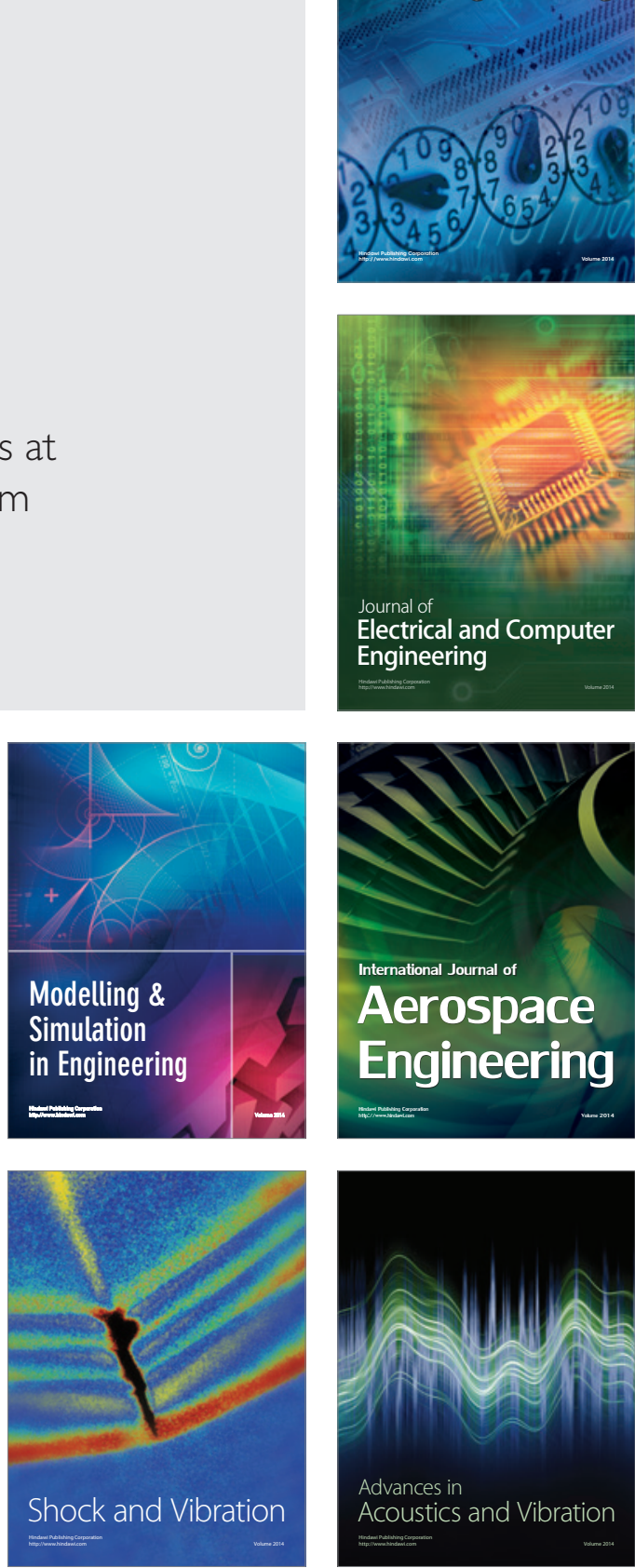